\section{THE STATE OF LUNACY IN ITALY.}

By G. Mackenzie Bacon, M.D.

Having long felt, with Keats, "a languishment for skies Italian," I gladly availed myself of an opportunity to visit a land so famous, and have spent in it and some other parts of the continent the last four months. During this period, I have made a point of seeing the principal asylums of the countries through which I passed; and beg to offer some of my impressions de voyage on these institutions.

The first feeling of every Englishman on visiting the continental asylums must, I imagine, be one of disappointment, so inferior are they, as a rule, to those of this country in size, comfort, and general arrangement. The wealth, political condition, religion, and even position, of a country, are each and all influences having a direct bearing on the state of its social institutions; and in all these points England differs very widely from other nations.

The liberty which this country enjoys has enabled local governments to provide for their insane poor almost at will, allowing a freedom of action which contrasts most favourably in its results with the centralised authority of paternal governments, whilst the wealth of the kingdom has furnished the most ample means for the furtherance of such beneficent efforts. On the continent generally, where the people have little or no share in the regulation of their own affairs, social reforms depend almost entirely on the will of an absolute ruler, and the character of the government is reflected in the institutions of the country.

In France, where revolution has for years distracted the land, the provision for the insane is lamentably bad and insufficient; and a people who are fond of considering themselves the first among civilised nations, cannot show more than two asylums equal to that which even the little Duchy of Baden has possessed for nearly twenty years. Austria, where everything is "royal and imperial", has produced but one modern asylum, though that is of the highest character. Switzerland-an oasis of liberty in the deserts of despotism-has some of the most creditable institutions on the continent. And Italy, so long "an house divided against itself," is only now taking the first steps in the much needed reforms. But, besides these points, the prevalent form of religion, the Roman Catholic, has had some influence in arresting progress; and in this way, that till recently the care of lunatics, in common with most exercises of public charity, devolved exclusively on the religious bodies. While it will be readily understood that the exclusive care of the insane by the religious classes, even in Catholic countries, is not a plan compatible with what is now considered proper management, I do not wish to convey the idea that the presence of these persons is always objectionable; for I am convinced I have seen their influence most usefully exerted, and attended by the happiest results. In Belgium, the insane are almost universally under the care of the religious, who perform their duties in the most conscientious manner. The difficulty which every superintendent feels in the management of an asylum-that of finding good and trustworthy servants, who take an intelligent interest in their work -does not exist in Catholic countries ; for in them their place is filled by a body who have no object in life, but the simple fulfilment of appointed duties, and who are protected by the aid of their religion from many of the fallibilities of those who mix more freely in the world. That their presence and moral influence are both respected, even by lunatics, and usefully exerted, may be gathered from the fact that they never meet with violence from their patients; and I have more than once seen a furious and illtempered woman obey instantly the gentle touch and ready smile of a sister of charity.

Whatever be the present condition of foreign asylums, one is glad to see that on all sides there are signs of progress; that everywhere the need of reform is admitted; and that in many places the work is commenced.

Thus, in France, the legislative body last year voted the sum of ten million francs, to be increased to fifteen if needed, for the construction of new asylums in the Department of the Seine, and nine are to be erected around Paris and within a short distance of the capital. When at Lyons, I was told that the authorities there had almost settled the plans for a new building, which would soon be commenced. In that city, at present, the lunatics share a very old hospital with syphilitic male patients, and children with skin-diseases, chiefiy of the scalp. I may also mention that, in June last, an imperial decree fixed the salaries of the asylum officials at the following rate throughout the whole of France. DirectorsFirst class, 7000 francs; second class, 6000 francs. Medical directors, 5000 francs. Medical officers-inchief, 4000 francs and 3000 francs. Assistant dittoFirst class, 2600 francs; second class, 2100 francs ; third class, 1800 francs.

Italy, as a whole, is so newly formed, and at present so imperfectly consolidated, that it is hardly fair to discuss the asylums in the recently acquired dominions now dependent on the government of Turin. Most of these establishments are still found in the cloistered buildings in which they took their origin; and in many the religious orders conduct the routine under a medical director; but, without exception, these houses are condemned by the directors, and are manifestly unsuitable for their present purposes. In Piedmont, the asylums are, though old, larger and better than in Central or South Italy; and in Genoa, there is a comparatively modern one ; but the newest and best was at Bassens, near Chambery, and formed, therefore, a part of the price paid by Italy to Napoleon for his "generous" assistance in the late war. At Milan, the great establishment of the Senavra is soon to be replaced by one more suitable in a different and more healthy situation; and this measure was even projected by the hated Tedeschi just previously to their expulsion. The only modern, and certainly the best, asylum in Central Italy, is at Reggio, in the old duchy of Modena. The building is well arranged, and the patients well cared for in many respects; but as I was positively refused admission to the quarter of the furiosi, this being never shown to strangers, I think we may conclude that there are some dark shades to this otherwise fair looking exterior. Perhaps, more interest attaches to the asylum at Aversa, near Naples, than to any other; for here has been placed as director one of Italy's most remarkable men -not to say heroes-Dr. Miraglia. This gentleman has distinguished himself by his study of phrenology among the insane, and by the zeal with which he has cultivated mental pathology, as well as by the interest he has taken in the improvement of the asylums in his country, and he has received from Victor Emmanuel the gold medal and cross of St. Maurice, the highest scientific honour; while he also enjoys the celebrity of having spent eight years in prison for expressing his opinions too fieely against the Bourbon government.

All the insane of South Italy were sent to the three 
houses at Aversa, where the accommodation was as bad as possible; but some new buildings have just been completed after. Dr. Miraglia's plans and are in excellent order.

Even at Rome, there are signs of improvement; and non possumus is by no means the motto of the Monsignore who directs the asylum. The most remarkable thing there is the suite of baths which has just been re-modelled, and deserves the highest praise; and the building has been enlarged and improved in many ways. I do not know that in any other part of the continent, the people are making such good use of their liberty to help themselves and raise their establishments to the level of the present day, as they are in the new provinces of the Italian kingdom; witness the following facts.

"The Council of the province of Milan has voted two million francs for the erection of an additional hospital for the insane poor of the province.

"The provincial deputation of Como, considering that the province requires an asylum for 300 patients, has ordered the erection of the same.

"The provincial Council of Bologna, in order to provide for the proper treatment of its lunatics, formed a commission of inquiry, composed of five professors, a lawyer, and an architect, who made suitable plans, and reported the urgent necessity of building a new asylum.

"The authorities of Bergamo have set about improving the asylum at Astino, substituted a better diet, and built an additional house to receive those capable of being employed."

There is, however, one feature in which Italy, though at every disadvantage, can give us a lesson; and that is, clinical instruction in lunacy, a matter virtually ignored in England. The Gazetta di Medicina Mentale regrets that there are only six Universities in Italy, where there is an "alienistic clinique." But how many has England? At Florence, Professor Bini; at Turin, Bonacossa ; at Bologna, Morti ; at Naples, Miraglia ; at Pavia and at Cagliari, Lumbroso and Dessi-Caboni-give instruction in this branch. illustrating their lectures by reference to actual cases and practice in the wards. Professor Miraglia, in his inaugural address at the University of Naples (March 1863), recounted how, in 1849 and previous years, he had, in his works, advocated the necessity of studying the physiology of the brain in connexion with insanity; and how, after being called a materialist and atheist by the priests in the service of the then government, he was forcibly silenced; and he does not seem to have escaped the same abuse on this occasion; for he mentioned a clerical periodical which raised the same cry, though happily with but little effect.

The Austrians, though half ruined by the necessities of their enormous army, have two new asylums in hand-one at Venice, where they are building a large and good house on the island of $\mathrm{S}$. Clemente for women only; and another at Ofen, in Transylvania. The latter is a very extensive three-storied building, and will be even superior to the magnificent one at Vienna, judging firom a photographic plan I was shown at the Ministry of the Interior, while staying in the Austrian capital. At Venice, the work, though urgently needed, goes on very slowly, so conscious are the Austrians of the uncertainty of the duration of their hated occupation.

At Frankfort-on-the-Maine, a new asylum is just completed, and will be occupied by patients in a few weeks. It has all the appointments we are used to see in England, and would rank with some of the best in this country. It is for the city of Frankfort, situated about a mile beyond the gates, and surrounded by several acres of land for cultivation.
With respect to the question of restraint,* I believe there is not one asylum on the continent where it is not practised and justified by the medical men; but in the better conducted there is much less of it than in others. In one asylum in Italy, I counted thirtythree women sitting in a long room, all restrained, either by means of a jacket, or by the hands being locked in a "muff"; but this was certainly exceptional.

At Vienna, I found the work of a celebrated German psychologist on European asylums, and turned with some curiosity to the account of the British. The date of the book is 1863 ; but the statistics given are of three years earlier, and the general description is fairly accurate; but there are some exceptions which would rather amuse the residents in the several places, and I noted a few as follows. The Bedford Asylum is said to have no bath accommodation and no water-closets; Cambridgeshire has only 100 patients; Cumberland has no asylum; at the Devon, there is mild restraint; at Colney Hatch, there is the only asylum-school in England; at St. Luke's, mild restraint; at Hanwell, the cures are only 3.5 per cent.; the Norfolk has only five acres of land; the Bethel (really an old-fashioned lunatic bospital in the heart of the city) is, we read, half-a-mile from Norwich, and part of the hospital; at Northampton and Stafford, there is mild restraint; while Oxford is particularised as having ten acres of land, attendants without uniform, non-restraint, and 18 per cent. of cures; the Surrey County Asylum, situated at Springfield, near Wandsworth, has only 4.10 per cent. cures, and is under the direction of Dr. Diamond, assisted by Drs. Biggs, Meyer, and Snape; at the York Retreat, restraint is practised "as in Germany"; at the North and East Riding, there is no padded room, "because Dr. Hill prefers the use of the jacket"; and the Wakefield is under tho charge of Dr. Gorsellis as sole medical man!! The licensed private houses are mostly, we learn, in the hands of lyymen, though there is a growing inclination to hand them over to physicians! The term "lunatic hospital" is evidently a stumbling block, and is always translated as meaning a division of a general hospital.

In one particular, the character of mental disease differs in Italy from that observed in other countries viz., that drunkenness is a very rare cause of disturbance of the brain-functions. In South Italy, where vice is by no means less prevalent than in England, inebriety is almost unknown, and a very uncommon cause of insanity; as one reaches further north, it becomes more frequent. In Lombardy, alcoholism is as potent for mischief as in Middle Europe; and in Sweden, Norway, and Russia the evil assumes serious proportions. It seems, indeed, as though one might map out the surface of Europe in zones according to the degrees of temperance observed by the inhabitants, in the same way as one makes zones for botanical purposes, knowing that certain plants and trees will be inet with in certain temperatures.

To these desultory remarks I may add one more; that, as regards treatment, the chief means relied on by foreign physicians is the use of baths of greater or less duration, but generally prolonged to a degree quite unknown in England.

Not wishing to be supposed to exalt English asylams at the expense of those on the continent, or to depreciate the really fine and good ones which exist in some places, I can only say, in conclusion, that while I believe we have, from our greater wealth and

* Since the above was written, Baron Mlundy's paper, "An Oasis in the Desert of German Restraint", has appeared, antounciug that Dr. Meyer "has had the courage to defend and practise the non. restraint system in the Hamburg Asylum." 
freedom in government, more and better asylums than other European nations, and a more rational treatment, no one can suppose we stand alone in our glory who has visited the splendid establishments which exist at Vienna, at Munich, at Illenau, and at Frankfort, or the Hospice Guislain, so near our shores as Ghent; and I have to acknowledge very gratefully the uniform courtesy I met with at the hands of the medical and lay authorities wherever I went.

\section{aeports of Sorietixs.}

\section{HARVEIAN SOCIETY OF LONDON.}

Thursday, March 3rd, 1864.

\section{W. Adams, Esq., F.R.C.S., President, in the Chair.}

Sudden Death. Dr. HICKMAN related the case of a man, aged 32, a butler, who had died suddenly. He had been quite well on going to bed; but a young man, going to call him in the morning, found him lying dead. On making an examination thirty hours after death, no changes were discoverable sufficient to cause death. The blood was fluid. There was no disease of the heart, or of the great vessels. The right side of the heart was flabby and full of blood. The brain and kidneys were healthy. Naturally suspecting that this might have been a case of suicide, Dr. Hickman removed the stomach. At the inquest, however, there was no evidence to prove that there was the least probability of suicide; nor was there any history of previous illness. Dr. Hickman not being able to pronounce as to the cause of death, the verdict was an open one. On examining the contents of the stomach, there was no poison found. Since the inquest, he had ascertained that the man had for some time complained of pain in the right side, and that he had had a fit some time before. For many years he had complained of pains in the right side on walking fast. Did he die of angina pectoris? The coronary arteries were not examined. The arteries in the brain appeared healthy.

Dr. BALLARD mentioned two cases of sudden death which he had witnessed. A healthy man, with orchitis, was lying on his sofa with a lotion on the testicle. He died suddenly, without any warning; and, on making a post mortem examination, no lesion could be discovered sufficient to account for his death. In the other instance, a magistrate, a patient of Dr. Ballard, had been at Goodwood races a few days before his death. On that day, at 12 noon, he was walking up and down Marylebone Lane. Being constipated, he requested Dr. Ballard to give him some medicine to relieve his bowels. Dr. Ballard sent him a draught, and also an enema; and was horrified, in about an hour afterwards, to hear that the patient had died while at stool. Post mortem examination disclosed ossification of the coronary arteries as the sole lesion in his body.

Mr. SEDGwICK related a case of sudden death. A young man went to bed feeling rather poorly ; and his landlady had given him some warm drink, as he felt chilly. When she awoke, she found that her lodger was dead, and had apparently been dead for some time. Mr. Sedgwick, on making a post mortem examination, could not discover any lesion sufficient to account for death; and the verdict was left open. The young man used oxalic acid in his business, but $\mathrm{Mr}$. Sedgwick could find none in the stomach.

Dr. Tilbory Fox mentioned the case of a coach- man of Dr. Walshe, who, having been ailing the day before, was brought into University College Hospital and died a few hours afterwards. No lesion was found to account for death. His urine was slightly albuminous; and possibly his brain might have become poisoned, and the heart's action thus stopped.

Dr. HICкMAN remarked, that uræmia rarely caused sudden death. He thought some alteration ought to be made in coroners' law, as there was a disposition on the part of juries to hurry on to a verdict in sucb difficult cases.

Spontaneous Gangrene in a Child. Dr. Cock mentioned a case of spontaneous gangrene occurring in a child eight years old. The child had been feverish for some days, when the left thigh began to swell about four inches above the knee upwards. There was no pulsation in the femoral artery or posterior tibial of the left limb. The limb was shrunken, mottled, and cold.

Dr. VINEN thought it probable that a plug of fibrine had occluded the artery.

Dr. Ballard said that Dr. Murchison had seen thirty or forty cases of phlegmasia dolens after typhoid fever; and that the left thigh was almost invariably the one affected.

Dr. Vrnes had lately had a similar case after typhoid fever.

Dr. Hickmas had lately seen a case of spontaneous sloughing of the skin in both feet, small in extent, but very painful; also a case of sloughing of the skin in the breast of a young woman without any specific taint.

Mr. AdAms had recently had under his care a case of phagedænic ulcer of the leg, extending deeply down, almost to the bone. There was no special history attached to the case, except that the patient, a girl, had been kicked on the part. This was the largest sloughing ulcer he had ever witnessed, and he had had much difficulty in making the foot useful. The girl was, however, now at service. He had also under his care now a case of sloughing of the skin of both feet from frost-bite. Both legs and feet were much swollen.

Death apparently from Inhalation of Sulphurous Acid Gas. Dr. Drysdale related a case where death had apparently been caused by the inhalation of sulphurous acid gas. The patient, aged 30, a healthy man, without hereditary taint, was with three other workmen engaged in a gallery in the Mint, when they became involved in the fumes of the gas. All became insensible. On recovery, the patient felt a tightness at the chest; and, a week afterwards, he had profuse hæmoptysis, after which the percussionnote was high pitched under both clavicles, more under the left. Profuse sweats ensued, bronchial breathing, and all the symptoms of rapid pulmonary phthisis. 'The patient walked about, but became very emaciated, and in four weeks became insane ; and, on being removed to Hanwell, he died suddenly. No post mortem examination was obtained.

Dr. VINEN mentioned the case of a child which became insane after drinking sulphuric acid. He thought that phthisis and insanity were nearly related.

Dr. T. Fox thought it possible that the case had been one of acute abscess of the lungs, without tubercles.

Dr. Cock observed that, although the man had had no hereditary predisposition to consumption, yet, being a townsman, he might have had a disposition to it, which was excited by the irritation of the gas.

Dr. Hrckmas thought that the delirium at the close of the case might have been caused by the occurrence of tubercular meningitis. 